\title{
How to achieve better outcome in treatment of asthma in general practice
}

\author{
Duncan Keeley
}

The symptoms of many asthmatic patients are poorly controlled, and there are several reasons why this may be so. Doctors fail to find out about symptoms that asthmatic patients are experiencing. Doctors wrongly assume that regular use of bronchodilators in small doses is satisfactory treatment for asthma and that taking high doses of bronchodilator in an asthma attack may be dangerous. Doctors think that inhaled steroids may be dangerous and are reluctant to use them in effective doses. Doctors do not check that patients can use their inhalers properly and do not make enough use of large volume spacers, the best available method for giving inhaled asthma treatment. Doctors undermine patients' confidence in advice on treatment by failing to ensure that consistent advice is given and often make the management of asthma more troublesome for the patient than the symptoms of asthma.

Surveys have shown that many patients with asthma remain poorly controlled even in well organised general practices that take an active interest in asthma care. Of patients surveyed in one study from Southampton, 51\% were waking at night with wheeze, $49 \%$ were wheezy at least once a week, $31 \%$ had missed school or work in the previous year, and $23 \%$ were avoiding certain physical activities between attacks. ${ }^{1}$ I would like to suggest some possible reasons why this should be the case.

The Health Centre, Thame OX0 3JZ

Duncan Keeley, general practitioner

\section{Doctors fail to identify asthmatic patients' symptoms}

During routine consultation with an asthmatic patient doctors often ask only very general questions

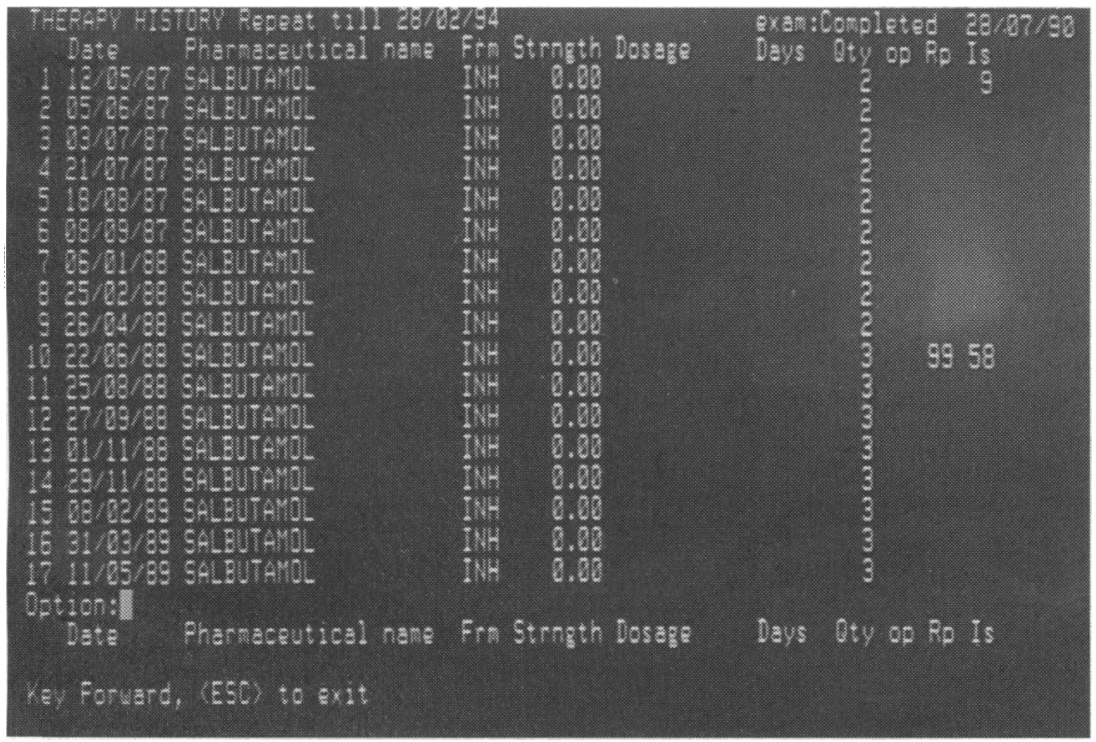

Treatment display screen for asthmatic patient. Record of repeat prescriptions should not look like this

such as, "How is your asthma?" to which the patient answers "Fine thanks," and no further details are ascertained. We would be more likely to identify patients with poorly controlled asthma if instead we were to ask questions such as, "In the past month has your asthma interfered with your ability to take exercise as you would wish?" "In the past month how many nights has your asthma disturbed your sleep?" and "In the past year how many days has your asthma made you so unwell that you could not go to school [go out to play] [do your usual work]?"

Questions like these can serve as a simple screening test to identify patients whose asthma needs better control. ${ }^{1}$ If we were to record the answers to these questions each time we reviewed a patient with asthma we would have a simple but adequate outcome measure with which to assess the effectiveness of our management. Routine recording and analysis of such information is possible with existing general practice computers. Such routine collection of outcome data would be a great advance, especially if there was a standard format for a simple morbidity index of this kind.

\section{Doctors think that regular use of bronchodilators treats asthma satisfactorily}

Patients like bronchodilators because they work quickly, but the need for regular use of bronchodilators is increasingly accepted as an indication of inadequate control. There is evidence that regular use of $\beta$ agonists may make asthma worse, ${ }^{2}$ and the British Thoracic Society guidelines suggest that the use of a $\beta$ agonist more than once daily is an indication for the introduction or increase in dose of prophylactic treatment. $^{3}$

This means that a patient who uses up a salbutamol inhaler in less than three months needs prophylaxis or more prophylaxis. A patient who regularly takes beclomethasone should use up at least two beclomethasone inhalers for every salbutamol inhaler, while a patient using sodium cromoglycate spincaps should use 336 capsules for every salbutamol inhaler. Regular repeat prescriptions should not authorise more reliever than preventer medication with each prescription, and prescribing analysis and cost (PACT) data at practice level 3 should not show a large excess of reliever over preventer inhalers being claimed. The best way to assess patterns of drug use is to look at the repeat medication record each time a patient is seen. This is particularly easy using the treatment display screen of a computer terminal (figure).

Doctors think that inhaled steroids may be dangerous and are reluctant to prescribe effective doses

Sodium cromoglycate should be tried first in children who need prophylactic treatment, but for 
$30 \%-50 \%$ of children it will be ineffective. ${ }^{4}$ It must be given at least three times daily. Its effect is rapidly lost when treatment is discontinued, and no greater effectiveness can be achieved by increasing the dose. In some cases, particularly when it is important to demonstrate the efficacy of prophylactic treatment reliably and quickly, it may be better to start with inhaled steroid and then step down to sodium cromoglycate if possible once control has been achieved.

The safety record of inhaled steroids at daily doses below $400 \mu \mathrm{g}$ for children and $800 \mu \mathrm{g}$ for adults is good. Even at higher doses clinically important side effects other than reversible oral thrush and dysphonia are rare. ${ }^{5}$ Large volume spacers should be the method of choice for giving inhaled steroid at any dose. They increase the lung deposition of inhaled steroids but greatly reduce the total absorbed dose by reducing oropharyngeal deposition. ${ }^{6}$

Recent publicity notwithstanding, inhaled beclomethasone has been prescribed for asthmatic children by paediatricians for 20 years without any significant problems with long term impairment of growth. ${ }^{7}$ It is simple and should be standard practice to chart the height of asthmatic children so that any fall off in linear growth can be detected and appropriate action taken. The dose at which to prescribe inhaled steroids may range from $100 \mu \mathrm{g}$ to $2000 \mu \mathrm{g}$ daily and should be considered carefully. For adults and older children the usual starting dose of inhaled steroid by metered dose inhaler should be $200 \mu \mathrm{g}$ twice daily. Doubling the dose of inhaled steroid at the start of an attack will often stop it becoming severe. Every asthmatic patient taking inhaled steroid should know when to do this and when to reduce the dose after an attack and after a prolonged period of good control.

\section{Doctors think that high doses of bronchodilator may be dangerous in an asthma attack}

Doctors, patients, and parents should know that inhaled treatments become ineffective during an asthma attack unless they are taken at much higher doses than usual. Thus treatment of an asthma attack requires regular administration of high doses of inhaled bronchodilator. One nebule of salbutamol contains the equivalent of 25 puffs from a metered dose inhaler $(2.5 \mathrm{mg})$, and large volume spacers are as effective as nebulisers in administering large doses of inhaled bronchodilator. ${ }^{89}$ Every asthmatic patient should have a large volume spacer and know how to use it. About 10-20 puffs of salbutamol every four hours via a large volume spacer (taken one puff at a time) is good treatment for an attack of asthma. Severe attacks will usually require treatment with oral steroids as well but will not invariably require admission to hospital.

Some bronchodilator inhalers still carry the legend "It is dangerous to exceed the recommended dose." This is not true: during an attack of asthma it is necessary to exceed the normally recommended dose if treatment is to be successful. The side effects of excess bronchodilator (tremor, tachycardia) are transient and easily recognised by a patient or parent. As an attack of asthma resolves the dose of bronchodilator should be reduced gradually. It is absurd to suddenly reduce the dose of inhaled salbutamol from $2.5 \mathrm{mg}$ every four hours to $0.2 \mathrm{mg}$ every six hours, but this is still often done.

All patients and parents need to know the indications for seeking medical advice in an attack of asthma. By denying them the knowledge of how to manage attacks effectively, doctors do not make it any more likely that patients will know when they should seek medical help. Indications for seeking medical help are if further bronchodilator is needed in less than four hours, if high doses of bronchodilator are needed for more than
12 hours, if peak flow falls below $50 \%$ of best, and if oral steroids are required.

\section{Doctors do not check whether patients use their inhalers properly}

One of the main reasons for the poor results of asthma treatment is that so little of the drug taken gets past the vocal cords. Poor technique with metered dose inhalers is the rule rather than the exception, and dry powder devices are not foolproof. Both types of inhaler deposit $85 \%-90 \%$ of the inhaled drug in the oropharynx even if used with perfect technique. ${ }^{610}$ Many patients who can demonstrate satisfactory technique in the surgery do not use their inhalers properly anywhere else, and almost no one uses inhalers properly in public. Patients should bring their inhalers when they come to the surgery, their inhaler technique should be checked at every visit, and they should be encouraged to use their best technique at all times.

\section{Doctors do not make enough use of the best available method for taking inhaled drugs}

Use of a large volume spacer with a metered dose inhaler achieves $20 \%$ lung deposition with only $15 \%$ of the dose deposited in the oropharynx. ${ }^{6}$ Thus, compared with other inhalers, large volume spacers deposit at least $30 \%$ more drug in the lung and deposit $60 \%$ less drug in the patient because of reduced oropharyngeal deposition (table). Equally important is the fact that, unlike other devices, they retain their effectiveness during asthma attacks. ${ }^{89} \mathrm{~A}$ metered dose inhaler with a large volume spacer should be the method of choice for inhaled treatment (see box). Dry powder devices are useful for daytime bronchodilatation in patients who cannot use metered dose inhalers on their own. Such treatment should only be needed occasionally in patients whose asthma is well controlled.

\section{Doctors fail to ensure that patients are given consistent advice and so undermine confidence in advice}

Patients and parents are often told different things about managing asthma by different doctors and nurses. This is a considerable cause of confusion and uncertainty and makes it less likely that treatment will be effective. Some patients may decide that the least confusing course of action is to ignore everything that health workers tell them. Many general practitioners have difficulty sharing the care of their patients with nurses trained in modern asthma management. Some doctors may dislike handing over part of a rewarding area of clinical practice to nurses, and others may disagree with some of the management strategies that practice nurses recommend. Primary care teams must work to overcome these problems to reach the maximum level of agreement over what patients are told and how. Hospital services-both in adult and paediatric medicine-likewise fail their patients if they do not do everything they can to ensure consistency in patient education. This is a continuing task because of staff turnover and of advances in management.

Consistency is just as important in technicalities

Pattern of deposition of drug with different inhalers. Values are percentages of total drug dose

\begin{tabular}{lccc}
\hline Site of deposition & $\begin{array}{c}\text { Dry powder } \\
\text { inhaler }\end{array}$ & $\begin{array}{c}\text { Metered dose } \\
\text { inhaler }\end{array}$ & $\begin{array}{c}\text { Metered dose inhaler } \\
\text { and large volume spacer }\end{array}$ \\
\hline Lung & $10-15$ & $10-15$ & 20 \\
Oropharynx & 80 & 80 & 15 \\
Device & 5 & 5 & 65 \\
Patient & 95 & 95 & 35 \\
\hline
\end{tabular}




\section{Advantages of large volume spacers}

- More effective treatment with fewer side effects because of better deposition pattern

- Problems of poor inhaler technique are largely overcome

- Easily used by children and elderly patients (except those with weak or arthritic hands)

- As effective as a nebuliser in treatment of acute attacks but light, cheap, maintenance free, portable, and prescribable

- Useful for treatment of first attacks of wheezing in patients who have not used inhalers before

- Useful for administration of bronchodilator when testing reversibility in the surgery to establish the diagnosis of asthma

- Reduced prescribing costs by basing treatment on the much cheaper metered dose inhalers

such as how to use an inhaler with a large volume spacer as in broader issues such as when to recommend prophylactic treatment. Patient held records can be useful in maximising consistency in what patients are told by different health workers. Such a record can include a written self management plan and a checklist showing which of the important topics in education about asthma have been covered.

\section{Doctors make management of asthma worse for patients than the symptoms}

Most of us prefer not to be ill, and many asthmatic patients prefer waking three times a week in the middle of the night for a puff on their inhaler (which they consider normal) to "having asthma" (which would mean that they were ill). Doctors and nurses play a large part in determining what it means for a patient to have asthma. Asthma varies enormously in its severity and impact-both between people and over time in the same person-and doctors need to be able to vary the fuss they make about it accordingly. A problem with management protocols is that they may activate a lot of unecessary intervention for people with mild disease. Both doctors and nurses are prone to make this mistake. When our patients do not comply with the treatment we recommend, we are apt to threaten them with the seriousness of undertreated asthma. We might be more successful if we made light of the diagnosis, thus making it easier for a patient to accept both the diagnosis and the treatment we are suggesting.

We must take the time to find out what each of our patients believes and fears about asthma and its treatment. Fears about the effects of steroids are particularly important. Only by listening to these concerns can we effectively address them. We will only persuade our patients to accept and use effective treatment if we make our management less threatening, less intrusive, and less fuss than the symptoms. This is a continuing challenge to our skills in communication and in organisation.

\section{Conclusion}

We have effective treatments for asthma at our disposal, but patients continue to suffer unacceptably high levels of morbidity. As in many other areas of medical practice we are failing to accord sufficient importance to the proper implementation of what we already know. For guidelines to be followed particular attention must be given to the promotion and justification of those management strategies in the guidelines which practising doctors find difficult to reconcile with previously held beliefs." It is also important (not least for medicolegal purposes) that guidelines are considered as guidance for the wise rather than for anyone's blind adherence.

These ideas were developed while I was working as GP coordinator for the Care of Asthma in Childhood based at the John Radcliffe Hospital, Oxford. This sessional post is funded by the Management Innovation Fund of Oxford Regional Health Authority. I thank Dr Anne Thomson, consultant paediatrician, John Radcliffe Hospital, for her comments on the first draft of this paper. Responsibility for any errors is mine.

1 Jones $\mathrm{K}$, Bain D, Middleton M, Mullee $\mathrm{M}$. Correlates of asthma morbidity in primary care. $B M \mathcal{F} 1992 ; 304: 361-4$.

2 Committee on the Safety of Medicines. Report of the Beta Agonist Working Party. London: Medicines Control Agency, 1992.

3 Guidelines on the management of asthma. Thorax 1993;48(suppl):S1-24.

4 Silverman $M$, Connolly N, Balfour-Lynn L, Godfrey S. Long term trial of disodium cromoglycate and isoprenaline in children with asthma. $B M F$ 1972;iii:378-81.

5 Geddes D. Inhaled corticosteroids: benefits and risks. Thorax 1992;47:404-7.

6 Newman S, Millar A, Lennard Jones T, Moren F, Clark S. Improvement of pressurised aerosol deposition with Nebuhaler spacer device. Thorax pressurised aeroso

7 Balfour-Lynn L. Growth and childhood asthma. Arch Dis Child 1986;61: 1049-55.

8 Morgan M, Singh B, Frame M, Williams S. Terbutaline aerosol given through a pear spacer in acute severe asthma. $B M \mathcal{F} 1982 ; 285: 849-50$.

9 Fuglsang G, Pedersen $S$. Comparison of nebuhaler and nebuliser treatment of acute severe asthma in children. Eur f Respir Dis 1986;69:109-13.

10 Newman S, Moren F, Trofast E, Talaee N, Clarke S. Deposition and clinical efficacy of terbutaline sulphate from Turbuhaler, a new multi dose powder inhaler. Eur Respir f 1989;2:247-52.

11 Delamothe T. Wanted: guidelines that doctors will follow. BMf 1993;307:218.

(Accepted 8 September 1993)

\section{COPING WITH CHANGE IN GENERAL PRACTICE}

\section{Learning from experience}

Doctors in a three partner practice do all their own on call out of hours work in an equal rota of nights and weekends. The senior partner is aged 56 . He has given vague hints that he is planning to retire at 60 but has never confirmed this. His two junior partners have been in the practice for three and four years respectively. At a partners' meeting he announces that he is proposing to give up his night work as he is finding this increasingly irksome, and has done it uninterrupted for the previous 27 years. $\mathrm{He}$ is proposing that the change should take effect from the beginning of the next quarter, in six weeks' time. His proposal is that the junior partners would take over his responsibility and in return would share all the income received for night visits. Much to his surprise he is met with an angry refusal. Hurt and rejected by this response, he gets angry and threatens to dissolve the partnership and the meeting breaks up in uproar. Most practices will be able to recall similar examples of proposed change going wrong. But most can also point to changes that have been successfully implemented and found to be beneficial. Change, or the possibility of it, is with us all the time. This ranges from the major externally imposed upheavals that have been a feature of general practice over the past few years to minor adjustments within the practice. All practices, therefore, have a wealth of experience of change. Can they use these experiences to improve their management of change? According to Socrates, experience has taught our best flautists, but it has also taught our worst.

Justin Allen and Andrew Wilson: Learning from the past. In Mike Pringle (ed), Change and teamwork in primary care, 1993. Available from the BMJ Bookshop, price $£ 7.95$. 